\title{
Perception of nursing students about couples' violence: knowledge, beliefs and professional role ${ }^{1}$
}

\author{
Assumpció Rigol-Cuadra ${ }^{2}$ \\ Paola Galbany-Estragué ${ }^{3}$ \\ Concepció Fuentes-Pumarola ${ }^{4}$ \\ Maria Dolors Burjales-Marti ${ }^{5}$ \\ Dolors Rodríguez-Martín ${ }^{6}$ \\ David Ballester-Ferrando ${ }^{7}$
}

Objectives: to analyse the knowledge, beliefs and perception of the professional role that nursing students have, about exerted violence against women in relationships. Method: a descriptive qualitative study following the ecological model through 16 focus groups realized with 112 students from four nursing courses of four Spanish universities. Results: the analytical categories were: knowledge, professional role, and beliefs about ones behaviour before the victim and the abuser. Students are unfamiliar with the characteristics of abuse, guidelines, protocols and screening questions and demand patterns for specific intervention. They do not identify their own professional role, be it delegated or specialized. Beliefs regarding their behaviour with the victim, not guided by professional criteria, perceive violence as a specific situation and disassociate the prevention of health care. They perceive the abuser as mentally ill, justifying the tolerance or delegation of performances. Conclusions: students define preconceived ideas about couples' violence. Speeches reproduce and reinforce stereotypical myths, values indicative of inadequate training for nursing studies which raises the need to fortify the competencies in relation to intimate couples' violence in the curriculum.

Descriptors: Violence Against Women; Health Knowledge, Attitudes, Practice; Education, Nursing.

\footnotetext{
${ }^{1}$ Supported by Escuela Universitaria de Enfermería, Universidad de Barcelona, Barcelona, Spain, process \# PREUI12/05.

2 PhD, Full Professor, Escuela Universitaria de Enfermería, Universidad de Barcelona, Barcelona, Spain.

3 PhD, Full Professor, Departamento de Enfermería, Universidad Autónoma de Barcelona, Cerdanyola del Vallés, Barcelona, Spain.

${ }^{4}$ PhD, Full Professor, Departamento de Enfermería, Universitat de Girona, Girona, Spain.

${ }^{5}$ Doctoral student, Universidad Rovira i Virgili, Tarragona, Spain. Professor Titular, Departamento de Enfermería, Universidad Rovira i Virgili, Tarragona, Spain.

${ }^{6}$ Doctoral student, Universidad Autónoma de Barcelona, Barcelona, Spain. Full Professor, Escuela Universitaria de Enfermería, Universidad de Barcelona, Barcelona, Spain.

7 Doctoral student, Universitat de Girona, Girona, Spain. Full Professor, Departamento de Enfermería, Universitat de Girona, Girona, Spain.
}

Corresponding Author:

Assumpció Rigol-Cuadra

Universidad de Barcelona. Escuela Universitaria de Enfermería

C/ Feixa Llarga, s/n

Campus de Ciències de la Salut de Bellvitge

08907, Barcelona, España

E-mail: arigol@ub.edu
Copyright (c) 2015 Revista Latino-Americana de Enfermagem

This is an Open Access article distributed under the terms of the Creative Commons Attribution Non-Commercial License (CC BY-NC).

This license lets others distribute, remix, tweak, and build upon your work non-commercially, and although their new works must also acknowledge you and be non-commercial, they don't have to license their derivative works on the same terms. 


\section{Introduction}

Couples' violence (La violencia de pareja VP) affects women of all social, cultural and economic status, given the current alarming proportions it has become an important public health problem(1), associated with high morbidity, mortality and health care costs(2).

The National Center for Injury Prevention and Control National(3) defines couples' violence as that which occurs between two people in an intimate relationship (including spouses, partners and ex-partner) over time, from a single episode to continuous episodes of violence, including four types of behaviours: physical violence, sexual violence, threats of physical or sexual violence and emotional abuse.

The usual field of VP is the family environment where, a situation of the male dominance is created over the woman and a reiteration of violent acts with harmful intentions. (4) Globally, it is reported that up to $38 \%$ of the murders committed against women, are carried out by their partners ${ }^{(1)}$.

The latest data from the European study of 2014 on violence against women, held between woman of the age of 18 and 74 member countries of the European Union, indicate that almost 62 million European women had suffered gender violence. $22 \%$ of the female participants reported having experienced physical and / or sexual violence by their partner or ex-partner(5).

Equally, the research conducted by the Pan American Health Organization (PAHO) said that violence against women inflicted by their intimate companion is widespread in all the countries of Latin America and the Caribbean. In the 12 countries where the study was conducted, although figures varied depending on the environment, women reported having experienced a few times act of violence by an intimate partner(6).

In the Spanish state the number of complaints registered in the first quarter of 2013 reached 29,487 cases, with an average of 327 daily reports(7), although violence against women has been identified as a determinant of poor health, the health sector has not committed itself enough to eradicate it. According to several authors ${ }^{(8)}$, women victims of VP attend health services more than others and have poorer health. However, there is an infra-detection ${ }^{(9)}$ and this is a concerning motive for the consequences for women and their health (physical and mental), as well as their quality of life.

The importance of screening and intervention from the health sector is obvious, therefore the World Health
Organization (WHO) ${ }^{(1)}$ recommends that all professionals in the health department, are to be trained to understand and act appropriately. Despite these recommendations, detection difficulties persist among health professionals due to among other reasons, insufficient training(10), attitudes and beliefs of professionals ${ }^{(11-12)}$.

Also, it has been observed that in some Latin American countries in the health field, violence is still an emerging issue that needs to be analysed by professionals; it is also necessary to develop help strategies to detect early situations of violence and intersectoral actions ${ }^{(13)}$.

These evidences suggest the need for nursing students to acquire during their training, knowledge and appropriate skills. Several authors corroborate the need to include training in VP in the nursing curriculum(14), with the goal of developing consistent practices and give visibility to this type of violence ${ }^{(10)}$ given the existing evidence regarding curricular deficiencies on the care nurses need to give in health services ${ }^{(15)}$. However, health professionals, particularly nurses are in a privileged position to identify and help female victims of VP because they are often the first contact within the health system be it in an emergency, community care or specialized services ${ }^{(9)}$. This position can enable them to offer help and support women in the search for alternatives. Even so, studies in this area indicate that nurses do not always feel prepared to intervene in the detection of abuse, keep track of process or give the necessary support when making a decision (16). The lack of knowledge and skills can favour nurses to focus solely on the physical care and forget providing comprehensive care(11).

Beliefs and myths in terms of those involved in the VP can influence the care health professionals provide. For what concerns the justification of abuse against women, professionals and students of Health Sciences highlight the mental disorders as a characteristic behaviour of aggressors(17). There are several myths, like the romantic love that justifies renunciation and sacrifice of women in many aspects of their lives ${ }^{(18)}$.

The present study aims to analyse nursing students from different Spanish universities (Barcelona, Tarragona and Girona), with the following concepts: knowledge, understood as the use of the theory for nursing practice and research(19); beliefs, defined as social representations that arise in everyday social interaction $^{(20)}$ and the perception of the professional role defining the professional role, according to the International Council of Nurses, as the key nursing roles 
in promoting health, preventing illness, restoring health and alleviating suffering ${ }^{(21)}$. Thus, the purpose of the study is to identify the obstacles and difficulties that may affect students in the subsequent exercise of the profession.

\section{Method}

Descriptive qualitative study realized during the academic year 2012-2013, in the Spanish universities of Barcelona (University of Barcelona and the Autonomous University of Barcelona), Tarragona (Rovira i Virgili University) and Girona (University of Girona). We chose this type of study because qualitative methodology incorporates perceptions and beliefs of the participants. On the other hand, the use of qualitative methodology and to stimulate reflection, allows for more comprehensive access to the representations that students have about the actions, beliefs and health practices towards the VP.

The framework of this research being part of the review of scientific literature is to promote awareness of the data and the comparison process. It began with different models for comprehension and action towards the VP: from gender theories, definitions and approaches of the OMS about VG(1) until the ecological model of Bronfenbrenner(22).

In the sample study showed 112 students, men and women between 19-35 years old. The aim was to have a wide variety of students from the most representative of Catalonia (Spain) public universities, considering that in each academic year an average of 400 students only enrol at the University of Barcelona, and 90-100 in other universities.

Data collection was conducted through focus groups with an average of 11 people per group from a pre-designed script. Questions were realized regarding knowledge and beliefs about the definition of violence against women, its causes were conducted, characteristics of the victim and the aggressor, attitudes towards the victim and the aggressor and the role and skills of the nurse towards the victims of VP. Homogeneous groups were formed to achieve maximum integration and interaction among participants.

The 16 focus groups represented one focus group for each university per academic year. This way at the University of Barcelona 27 students participated, in the Autonomous University of Barcelona 31, at the University of Girona 30 and at the University Rovira and Virgili 24.
Researchers actively participated in moderating discussion groups, raised the interview questions in the same order and without influencing the responses and discussion of participants; They showed neither agree nor disagree in the speech of participants, or the verbal language or nonverbal. Before each session of a focus group and after each sessions of analysis and monitoring of activities with the research team in order to analyse and resolve the doubts, problems or conflicts that may have performed emerged. In each session the consent of all those who participated in the study was requested.

The selection of participants was made by convenience sampling and students participated voluntarily. We contacted them in September 2013, when the academic year started. After being informed about the study, they signed a consent document and were told that their responses would be confidential, receiving a code to preserve their identity. Previously, the study was approved by the Commission for Bioethics at the University of Barcelona, who led the research "Multi centric study on the perception of couples' violence in nursing students"; authorization has also been requested to the other participating. The researchers agreed in returning the results to the university, once the study was done and published.

The meeting took place in a classrooms in each of the universities, from October to December 2013 and January-February 2014. The interviews lasted around an hour and were recorded on a tape recorder for later transcription. Information was collected until data saturation.

The results were triangulated with the bibliography of information. Analyses were performed by two different researchers from the focus groups. The obtained results were organized in codes and categories. Analytical categories were: knowledge, professional role, and beliefs about the proceedings before the victim and to the aggressor.

\section{Results}

\section{Knowledge}

For the knowledge category the identified codes were: performance strategies, standard guidance and unawareness on VP.

In regards of strategies of performance in relation to the process of VP, predominant concern for guidance standards and students demanded patterns of specific and targeted interventions: I wonder if there is a protocol 
in nursing we should know in the event of a possible suspect of gender violence (GBV) (E14).

Unawareness was reflected in some statements that were made by students, focusing on the detection of the most common symptoms that may present the victims, regardless of the risk factors that allow early detection and preventing the problem. Know the warning signs, and know when you might come across a situation where a person has suffered from physical and psychological (E2).

The students were unaware that female victims of VP, attended health care more than others and have poorer health, with high levels of stress and psychological problems. Also, many times unaware that their symptoms appeared masked with other symptoms: repeated consultations for trivial symptoms, somatization, nonspecific psychological distress and increased use of antidepressants.

\section{Professional role}

For the professional role category, it coded: biomedical vision, not assuming the proper role, nursing skills, delegated care and social role.

Regarding the professional role a clinical and biomedical vision persisted of violence against females was limited to physical damage and excluded health problems arising from psychological abuse. From this reductionist view, the students eluded aspects such as social isolation, creating feelings of worthlessness and helplessness, or continuous personal control by the spouse that impede identifying the full range of psychological and behavioural symptoms, prior to physical abuse, causing serious health consequences which they suffered from and often go unnoticed: Know the signs and symptoms of the abused person (E3).

The students did not assume an own profession attention to violence, ignoring the holistic and ecological vision: It can be very difficult for an abused woman to trust a nurse (E4). They considered that the assumption of this professional responsibility was outside of their jurisdiction and meant neglecting the welfare work. In addition, they associated resource scarcity and lack of preparation to the difficulty of providing comprehensive care to women victims of VP: It would mean neglecting the welfare work (...) we do not have sufficient resources (E8). What the nurse can do is note it down and refer to another professional, but we lack preparation for working with women (E24).
One of the reasons justifying the delegation was the lack of competence assumption: The nurse does not have a prominent role, who must intervene here is a social worker or a psychologist (E19), or the identification of a specialized role: It must be a nurse specifically dedicated to all issues of couples' violence (E29). Nevertheless, they considered their professional role important from a social perspective: Nursing has a very important role in society, you're a person close to the people, who can tell you what they feel ... in this case we can detect problems early (E30).

\section{Proceedings towards the victim}

Regarding beliefs about the performance with the victim, emerging categories were: personal ethical standards, training activities, receptive attitude, information, dangerous attitudes, secondary victimization, prevention and detection.

Some students were based on personal ethical standards without considering the need to abide by professional standards, in which the ethical perspective is conferred duties and giving information on how to act in certain situations: Acting as our ethics, notify a psychologist (E7).

They did not either consider that control and isolation strategies were part of the abuse, and presented entertainment to reduce stress and increase well-being. This action could generate feelings of guilt on the victim, because it aggravates the problem without offering appropriate solutions: Even if it is not physically, doing activities to relax, questions, do activities outside your home environment (E5).

Although identified the need to show a receptive attitude that facilitates verbalization of the problem and to establish a relationship of trust, the students did not consider the difficulty that many of the female victims of violence have, and to recognize and denounce attacks since the start. They also limited the professional behaviour of information, as if the fact of reporting was sufficient to produce changes in such a complex process: Sensitivity too, (...) empathy (...), active listening. Create a framework of trust and that person only tells you once and after recognizing, you inform. Give information and from now on, the decision is up to the patient. (E65).

Some of the students responses also showed dangerous attitudes of unawareness toward the VP cycle and saw it as something specific: Reassure the victim that 
the partner will not re-do it (E45). You can give the phone number for when the abuse happens (E101).

This draws attention to some of the answers of secondary victimization, blames women themselves from a rehabilitation perspective; Re-educate this person so that it does not happen again (E98).

Although some students mentioned the importance of prevention: (...) I believe that the nurse has a role in prevention, campaigning and consulting the CAP (E41), generally they do not integrate to primary health care (she / it will refer to the CAP as Primary Care Centre), downplaying the health system, which to some extent justified the lack of involvement of nurses in the prevention and detection: Talking in institutes, and at schools (E45).

\section{Proceedings before the aggressor}

For beliefs category about attitudes towards the aggressor codes were identified: popular imagination, mental disorders, psychological problems and romantic love.

The speech of the participants reflected beliefs that are part of the popular imagination, that legitimate and minimize the problem and contradict the findings produced by research. An example of this would be that one of the causes of the VP is that the offender has a mental illness, a psychological disorder, or an addiction. From this assumption, the configuration profile offenders as subjects in need of understanding and healing: As a nurse you have to let the other person reinsert itself in society, always when this person is curable. (...) Man! Of course! All offenders have a problem (E97).

The belief that the abuser has psychological problems, justified tolerance and limitation of actions. The students did not take into account the fact that having a mental disorder does not mean not knowing how to take responsibility, because at some point this could be an aggravating factor, it is not the cause that justifies the abuse, because people with mental disorder does not mean they have to be abusers: As nurses, we have to understand and help these people. If the abuser comes to tell you that they have a problem, they are already being healed (E66). Talk with a professional because there is a pathology, you may need therapy and nurses do not have enough knowledge. (E70).

The students also showed instinctive attitudes, more related to the imaginary itself than with a professional performance: The man who is violent, deserves to be punished (E22).
Romantic love is another myth that appeared in discussions. The cultural model of love proposes self-renunciation and sacrificing the existence of independence in order to make the other person the centre of one's life. Individuality, ideas, projects and goals cease to be the main thing in a woman life in order for someone else to take the place. This leads to losing her personality and the emergence of a huge dependence; we live by and thanks to the other. The woman learns to give up, to give pleasure and not receive the same from her partner: And the way the person is, I don't know, might even be in love (...) little by little, by being mistreated, they fully lower themselves (E49).

Misconceptions of love and relationships with certain behaviours, authority, jealousy, control, being obvious that when men use violence what they are aiming for is to perpetuate submission. From this perspective, affection aggression is separated and it is seen as a personal control that is justified in terms of other qualities: controlling and if needed, see it as a sick person, try to help, provide that psychologists, welcome with open hands with everything we have, so that the person can or intends to change (E101).

\section{Discussion}

Regarding the category knowledge it is relevant to mention that most students interviewed said to not having acquired the needed knowledge of the VP, nor symptoms that women can present ${ }^{(23)}$. Despite feeling sensitized, they believe they are not prepared to end their career. The proposed intervention strategies agreed more with the popular knowledge than with specific training, that was projected in attitudes both to the victim and to the aggressor, which may aggravate the situation of violence and where prevention was absent ${ }^{(24)}$. This fact reveals the lack of content during their training, both theoretical and practical, in contradiction with the guidelines of international and national agencies ${ }^{(1.25)}$.

Some authors suggest that nurses, after completing their studies, are poorly prepared to provide care for female victims of VP and nurses who are trained do so, the majority $(48 \%)$, by own initiative ${ }^{(15)}$. Professionals are aware that the VP is a significant prejudice to the health of women and recognize their limitations in knowledge, they feel the need for a better preparation in order to provide better care, proposing actions to improve their study through training, sessions, discussions in multidisciplinary teams, providing activities in health centres and even 
through agreements with the University ${ }^{(10)}$. Some research finds that, students who have received VP training before graduation, perceive greater knowledge and skills to professionally manage VP cases $^{(14)}$. In this situation, the professionals suggest the possibility of including the VP theme in the current graduation curriculum, through practices and clinical experience ${ }^{(15)}$.

Regarding the professional role, discourse analysis indicates, in part, a lack of knowledge of this, even though they interviewed seniors who has realized the practices in the previous key point. This shows that they had not internalized the concept of what the professional role is, or did not receive any training / information nor by the tutors or professional assistance, even though the primary health care and the professionals constituted a key environment as a detection and integrated approach, both for its accessibility, such as the possibilities of relationship with the patient. This lack of transmission of skills, in relation to the VP, shows that Spanish Law on Integral Protection Measures against Gender Violence of 2004 is known for a small percentage of professionals(25).

The students do not understand that the care and support of victims should be one of the responsibilities of nursing, and therefore do not take ownership of the profession's attention to violence, ignoring the holistic and ecological vision(24).

Insufficient training / information that could not have been given to the students by tutors or professionals in primary care centres in Spain, shows that, there may be also a lack of care coordination. In addition, the students associated the scarcity of resources and lack of preparation to the difficulty of providing comprehensive services to female victims of violence care, consistent with some of the studies in the Spanish state ${ }^{(24)}$.

The beliefs and stereotypes persist in relation to women, like the vision of romantic love(18) or the attribution of mental disorders aggressors ${ }^{(17)}$, leads to erroneous actions.

Through speeches we can say that the students conceive violence against women as a social problem. Such violence is rooted in gender relations based on inequality, from sexual dimorphism structure social relations, giving meaning and content to what is being man and woman in society. For this social construct, it is attributed to male supremacy and therefore the legitimacy to exercise power over the female, thus omitting a view from complex ecological models that facilitate care from the health sector. These beliefs impede the detection of abuse in the ED, an example of this are the results from a qualitative study in the US revealing that in assessing nurses towards VP victims in an emergency, premium perception in relation to the potential victim before the protocol suggested by the organization(11).

In this vein, several authors stress that insufficient knowledge, misconceptions about the role nurses in detection and intervention as well as the myths related to socioeconomic status, ethnicity, nationality or culture of the perpetrators and victims of violence, act as barriers to professional appropriate intervention in cases of $\mathrm{VP}^{(12)}$. Hence the importance of focusing on nursing studies efforts to train future professionals and educators in this area.

\section{Conclusion}

The interviewed nursing students have a lack of training on the phenomenon of the VP, unaware of interview guidelines and protocols which does not include the prevention, detection and intervention as part of the professional role from a holistic and ecological perspective.

The perception of the VP as "social" health problem transcends competition, avoids involvement and therefore identify the professional role. The ignorance of the phenomenon of VP is reflected in popular beliefs and attitudes that scientific, sometimes dangerous for the victim and the aggressor tolerant.

This raises the need for specific and transversal contents on violence against women in the curricula of the Degree of Nursing, and a joint working between care and teaching, and the training of health professionals is the main route for early detection of violence against women, assistance and referral.

\section{References}

1. World Health Organization (WHO). Global and regional estimates of violence against women: prevalence and health effects of intimate partner violence and nonpartner sexual violence [Internet]. 2013. [acesso 14 jan 2014]. Disponivel em: http://apps.who.int/iris/ bitstream/10665/85239/1/9789241564625_eng.pdf

2. Ruiz Peña M, González Peña MJ, López Álvarez JM, Iglesias Hernández MI, Barros Rubio C, González Amaya $S$. Violencia de género en un área de salud. Semer-Med Fam. 2010;36(4):202-7. 
3. Center for Injury Prevention, Control. Understanding intimate partner violence: Fact sheet [Internet]. Centers for Disease Control and Prevention, Atlanta, GA. 2009. [acesso 22 jul 2014]. Disponivel em: http://www.cdc. gov/violenceprevention/pdf/IPV_factsheet-a.pdf

4. Sala Musach I, Hernandez Alonso AR, Ros Guitart R, Lorenz Castañe G, Parellada Esquius N. Domestic violence: a screening question. Aten Primaria. 2010;42(2):70-8.

5. European Union Agency for Fundamental Rights. Violenc against women: an EU-wide survey Main results [Internet]. Luxemburg: Publications Office of the European Union, 2014 [acesso 5 abril 2014]. Disponível em: http://goo.gl/1gLsv3

6. Bott S. Guedes A, Goodwin M. Adams J. A Violence Against Women in Latin America and the Caribbean. A comparative analysis of population-based data from 12 countries [Internet]. Washington, DC: PAHO, 2013. [acesso 5 abril 2014]. Disponível em: http://www.igwg. org/igwg_media/guedes-gbv-lac.pdf

7. Observatorio contra la Violencia Doméstica y de Género. Consejo General del Poder Judicial [Internet]. Estadística del Observatorio: caen las denuncias de violencia de género un $5 \%$ en el primer trimestre de 2013. [acesso 20 jun 2014]. Disponível em: http://www.observatorioviolencia.org/documentos. php?id=316

8. Montero I, Ruiz-Perez I, Martín-Baena D, Talavera M, Escribà-Agüir V, Vives Cases C. Violence against women from different relationship contexts and health care utilization in Spain. Womens Health Issues. 2011;21(5):400-6.

9. Arredondo-Provecho AB, Del Pliego G, Nadal M, Roy R. Conocimientos y opiniones de los profesionales de la salud de atención especializada acerca de la violencia de género. Enferm Clín. 2008;18(4):175-82.

10. Salcedo-Barrientos DM, Orchiucci Miura $P$, Dias Macedo V, Yoshikawa Egry E. How do primary health care professionals deal with pregnant women who are victims of domestic violence?. Rev. Latino-Am. Enfermagem. 2014;22(3):448-53

11. Robinson R. Myths and Stereotypes: How Registered Nurses Screen for Intimate Partner Violence. J Emergency Nurs. 2010;36(6):572-6.

12. Tufts $K A$, Clements $P T$, Karlowicz KA. Integrating intimate partner violence content across curricula: Developing a new generation of Nurse Educators. Nurse Educ Today. 2009;29(1):40-7.

13. Alves RB, Rosa EM. Prevenção da violência na adolescência: propostas existentes no Brasil e as possibilidades de atuação na saúde pública. Adolesc Saude. 2013;10(3):45-60

14. Beccaria G, Beccaria L, Dawson R, Gorman D, Harris J, Hossain D. Nursing student's perceptions and understanding of intimate partner violence. Nurse Educ Today. 2013;33(8):907-11.

15. Sundborg EM, Saleh-Stattin N, Törnkvist L. Nurses preparedness to care for women exposed to intimate partner violence: a quantitative study in primary health care. BMC Nurs. [Internet]. 2012. [acesso 24 jul 2014]; 11:1. Disponível em: http://www.biomedcentral.com/ content/pdf/1472-6955-11-1.pdf

16. Almutairi G, Alrashidi M, Almerri A, Kamel M, ElShazly $M$. How to screen for domestic violence against women in primary health care centers. Alexandria J Med. 2013;49:89-94.

17. Rigol A, Sánchez I. Estudio de la percepción que tienen estudiantes universitarios sobre las medidas a adoptar para prevenir y erradicar las violencias contra las mujeres. Enfermería Comunitaria. Rev Int Cuidados Salud Familiar Comun. [Internet]. 2007 [acesso 13 jan 2014];3(1). Disponível em: http://www.index-f.com/ comunitaria/v3n1/ec6458.php

18. Ferrer VA, Bosch E. Del amor romántico a la violencia de género. Para una coeducación emocional en la agenda educativa. Profesorado. Rev Curriculum Formación de Profesorado. 2013;17(1):105-22.

19. Duran de Villalobos MM. La teoría, soporte de la ciencia y práctica de enfermería: tendencias. Av Enferm. [Internet]; 2012 [acesso 13 han 2014];30(1):912. Disponível em: http://www.index-f.com/ rae/301pdf/009012.pdf

20. Melgueizo Herrera E, Alzate Posada ML. Ciencia y prácticas en el cuidado de salud. Av Enferm. [Internet]. 2008 [acesso 13 han 2014];26(1):(112-123). Disponível em: http://www.scielo.org.co/pdf/aven/ v26n1/v26n1a12

21. Zabalegui Yarnoz A. El rol del profesional en enfermería. Aquichán. [Internet]. 2003 [acesso 13 han 2014];3(1):16-20. Disponível em: http://www.redalyc. org/articulo.oa?id=74130304

22. Bonino L. Desvelando los micromachismos en la vida conyugal. En: Corsi J, editor. Violencia masculina en la pareja. Una aproximación al diagnóstico y a los modelos de intervención. Buenos Aires: Paidós; 1995. p. 191208.

23. De la Fuente Aparicio $D$, Salamanca Castro AB, Sánchez Castro $S$. ¿Se encuentran capacitadas las enfermeras para detectar malos tratos en Atención Primaria? Nure Invest. 2005;15:1-10. 
24. Echarte JL, León N, Puente I, Laso De La Vega S, Díez E, Martínez MT. Mejorar la calidad asistencial en la atención a la mujer maltratada en los servicios de urgencias. Emergencias. 2010;22(3):193-8.

25. Ley orgánica n. 313 de 28 de diciembre de 2004 (ES). Medidas de Protección Integral contra la Violencia de Género. Bol Of Estado [Internet]. 29 dic 2004. [acesso 30 jul 2014]. Disponível em: http://www.boe. es/diario_boe/txt.php?id=BOE-A-2004-21760 